\title{
Mineralocorticoid receptor antagonists: their use and differentiation in Japan
}

\begin{abstract}
Atsuhisa Sato
In the presence of salt, aldosterone causes hypertension and organ damage via the mineralocorticoid receptor (MR) through various mechanisms. MR antagonists are considered to be potassium-sparing diuretics that exert their effect by blocking MR in the kidney, and they are not the first choice for treating hypertension. However, the importance and usefulness of inhibiting aldosterone in the management of hypertension have recently been revealed in both the basic and clinical fields. In Japan, both the selective MR antagonist eplerenone and the non-selective MR antagonist spironolactone are indicated for the treatment of hypertension. Although these drugs are generally used in the same manner, in some cases they require differentiation. This differentiation is divided into two types due to the differences in their features and differences in their contraindications in Japan. Based on a number of studies on MR antagonists that have been recently published, the diseases and clinical conditions targeted by MR antagonists appear to be likely to increase in the future. In Japan, we consider it necessary to carefully differentiate spironolactone from eplerenone in regard to their intended uses.
\end{abstract}

Hypertension Research (2013) 36, 185-190; doi:10.1038/hr.2012.182; published online 22 November 2012

Keywords: aldosterone; chronic kidney disease; eplerenone; mineralocorticoid receptor antagonists; spironolactone

\section{INTRODUCTION}

The Japanese Society of Hypertension Guidelines for the Management of Hypertension (JSH 2009) stipulates that an antihypertensive drug should initially be administered as the first choice of treatment as monotherapy or in combination therapy, and five types of antihypertensive drugs are listed. ${ }^{1}$ These drugs exert sufficient hypotensive effects and are tolerated by hypertensive patients. However, there are few patients for whom blood pressure is controlled by monotherapy. Hypertensive patients need to be treated with an efficient combination therapy using the most effective drug. JSH 2009 stipulates that the combination used should be supported in comparisons in largescale clinical trials. A typical example of such a combination is angiotensin-converting enzyme (ACE) inhibitors or angiotensin II receptor blockers (ARBs) and diuretics. Mineralocorticoid receptor (MR) antagonists are considered to be potassium-sparing diuretics that exert their effect by blocking MR in the kidney. MR antagonists are differentiated from diuretics, primarily thiazide diuretics, and are not the first choice for treating hypertension. However, the importance and usefulness of inhibiting aldosterone in the management of hypertension have recently been revealed in both the basic and clinical fields. ${ }^{2-4}$

In this paper, we discuss the use of MR antagonists in Japan. In Japan, eplerenone, which is a selective MR antagonist, is indicated for the treatment of hypertension. Both spironolactone, which is a non-selective MR antagonist, and eplerenone can be used for the treatment of hypertension. These drugs are used in the same manner. However, in some cases, these drugs need to be differentiated. The drugs can be differentiated by two characteristics: their features and their contraindications in Japan (Table 1).

\section{PHARMACOLOGICAL CHARACTERISTICS OF SPIRONOLACTONE AND EPLERENONE}

Both spironolactone and eplerenone target MR for the management of hypertension. However, there is controversy regarding the ligand. $\mathrm{MR}$ in epithelial tissues and MR in non-epithelial tissues are genetically identical, ${ }^{5,6}$ but they differ substantially physiologically; therefore, the ligand is difficult to determine. Compared with spironolactone, eplerenone has two specific features. First, eplerenone is highly selective for MR. ${ }^{7}$ Because it does not act on other steroid receptors, it rarely causes endocrine side effects. In contrast, spironolactone contains elements of the progesterone molecule, and its use is accompanied by progestogenic and antiandrogenic adverse effects, such as painful gynecomastia, menstrual irregularities and impotence. ${ }^{8}$ Additionally, the $\mathrm{IC}_{50}$ value of eplerenone for $\mathrm{MR}$ is $\sim 40$ times higher than that of spironolactone; that is, eplerenone has a weaker MR antagonism than spironolactone. ${ }^{9,10}$ Furthermore, some metabolites formed after spironolactone has been metabolized in the liver. These metabolites also show MR antagonism. ${ }^{11,12}$ In regard to titers, $7 \alpha$-thiomethylspironolactone 
Table 1 Indications and contraindications of spironolactone and eplerenone in Japan

\begin{tabular}{|c|c|c|}
\hline Indications & $\begin{array}{l}\text { Hypertension (essential, renal and so on) } \\
\text { Cardiac } \bullet \text { renal } \bullet \text { hepatic } \bullet \text { idiopathic edema } \\
\text { Edema and/or ascites associated with malignancy } \\
\text { Diagnosis and/or improvement of symptoms of primary aldosteronism }\end{array}$ & Hypertension \\
\hline Contraindication & $\begin{array}{l}\text { Patients with anuria or acute renal failure } \\
\text { Patients with hyperkalemia } \\
\text { Patients with Addison's disease } \\
\text { Patients treated with tacrolimus or eplerenone or mitotane } \\
\text { Patients with allergy to spironolactone }\end{array}$ & $\begin{array}{l}\text { Patients with hyperkalemia or serum potassium level above } 5 \mathrm{mEq} \mathrm{I}^{-1} \\
\text { Diabetic patients with microalbuminuria or proteinuria } \\
\text { Patients with moderate or severe renal dysfunction }(\mathrm{Ccr}<50 \mathrm{ml} \text { per minute) } \\
\text { Patients with severe liver dysfunction } \\
\text { Patients treated with potassium preparation or potassium sparing diuretics } \\
\text { Patients treated with itraconazole or ritonavir or Nelfinavir } \\
\text { Patients with allergy to eplerenone }\end{array}$ \\
\hline Doses & 50-100 mg per day & 50-100 mg per day \\
\hline
\end{tabular}

Abbreviation: Ccr, creatinine clearance.

Table 2 Representative pharmacological characteristics of spironolactone and eplerenone in Japan

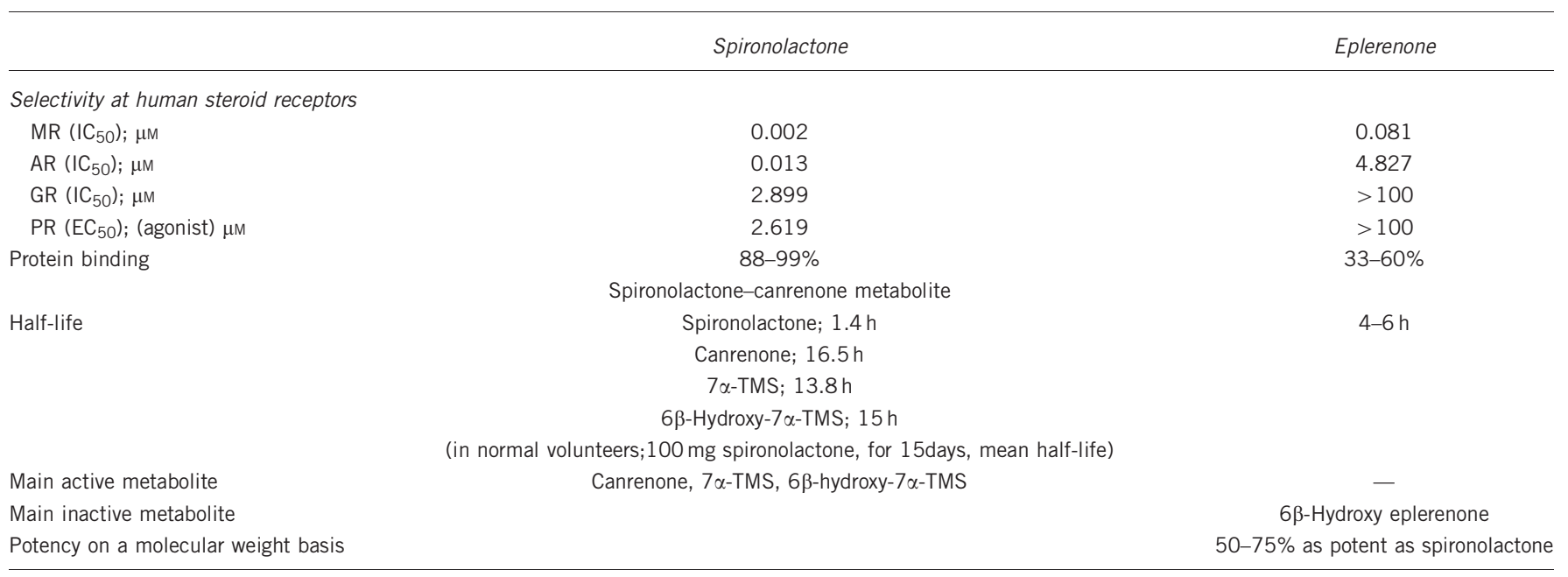

Abbreviations: AR, androgen receptor; GR, glucocorticoid receptor; MR, mineralocorticoid receptor; PR, progesterone receptor; TMS, thiomethylspironolactone. Adapted from Garthwaite and McMahon ${ }^{7}$ and Sica. ${ }^{13}$

and the metabolite canrenone show only $\sim 30 \%$ of the MR antagonism exhibited by spironolactone. However, the blood concentrations of $7 \alpha$-thiomethylspironolactone at its peak are approximately threefold higher compared with spironolactone. In contrast, eplerenone itself is an active form. Its metabolites (the main metabolite is $6 \beta$-hydroxy eplerenone) have no MR antagonism. ${ }^{13}$ In this regard, the percentage of the protein binding of eplerenone in vivo is lower than that of spironolactone. Therefore, the severity of $\mathrm{MR}$ antagonism in vitro cannot be a direct indication in vivo, but eplerenone is a weaker MR antagonist compared with spironolactone. Therefore, it has been reported that eplerenone elicits smaller changes in renin-angiotensin-aldosterone axis components than spironolactone. These results are clinically reflected by eplerenone barely increasing serum potassium values at its hypotensive dose. ${ }^{14}$ Representative pharmacological characteristics of spironolactone and eplerenone are summarized in Table 2. Clinically, the differences between these two drugs pertain to their potency (a higher MR antagonistic activity for spironolactone than for eplerenone at the same dose level), half-life (longer with the spironolactone metabolite), likelihood to induce hyperkalemia (although both drugs should be used carefully, the incidence is lower with eplerenone at the same dose level because of its lower MR antagonistic activity) and endocrinological adverse reactions (the incidence with eplerenone is comparable to the placebo). In Japan, because the contraindications listed in the package insert differ between eplerenone and spironolactone, as described later, the selection of eplerenone or spironolactone based on the features of individual cases is essential, although these two drugs can be applied under a common strategy for both drugs in other countries. Another important issue when using these drugs in Japan pertains to the drugs' prices under the National Health Insurance system. The National Health Insurance price of eplerenone in Japan is lower than its price overseas. In Japan, eplerenone is indicated for hypertension (a characteristic unique to Japan in contrast to most other countries, where it is used for the management of heart failure and sold at higher prices). In this sense, switching from spironolactone to eplerenone (for example, in cases showing endocrinological adverse reactions) may not be financially stressful for patients in Japan. It is essential to bear these diverse viewpoints in mind when the two drugs are positioned clinically instead of simply arguing about whether spironolactone or eplerenone is superior. 


\section{USE BOTH DRUGS IN THE SAME MANNER}

In light of these differences in the features of the two drugs, we considered the actual clinical uses. First, we describe some of the clinical conditions for which both drugs are used in the same manner. In such cases, there is no difference between the two drugs. Both drugs should be monitored for their efficacy and safety during their use. If a patient experiences no adverse reaction to spironolactone and the blood pressure is well controlled, then there is no need to change spironolactone to eplerenone or vice versa.

\section{Primary aldosteronism}

Primary aldosteronism (PA) is a secondary hypertension caused by the autonomous excessive secretion of aldosterone from the adrenal gland. Screening for PA has recently drawn attention because PA occurs more frequently than previously expected and is curable by operative therapy. From 2008 to 2009, the Endocrine Society, the Japan Endocrine Society and the Japanese Society of Hypertension published guidelines on PA. The objective in treating PA is to control hypertension and suppress the direct organ disorders caused by the hypersecretion of aldosterone. There are both operative therapies and internal therapies, primarily the use of MR antagonists. The more frequently PA occurs, the more a discussion of the results of medical therapy is needed. However, it is highly possible that some studies comparing operative therapy and medical therapy may include study patients who are substantially different between the treatment groups. Therefore, direct interpretation is problematic. There is no study that accurately compares the prognosis of both treatment groups.

Catena et al. ${ }^{15}$ compared the rate of regression of left ventricular hypertrophy in patients whose PA was treated by operative therapy or spironolactone therapy. The regression of left ventricular hypertrophy was noted 1 year after beginning treatment in $\sim 15 \%$ of patients receiving operative therapy and $\sim 5 \%$ of patients receiving spironolactone therapy. At the end of the study (mean 6.4 years), more patients in the spironolactone therapy group exhibited regression, and the difference between the two groups was reduced ( $\sim 20$ and $\sim 15 \%$, respectively). During the course of the study, both therapies provided comparable blood pressure control. Sechi et al. ${ }^{16}$ compared the relatively long-term change over time of the renal function in PA between operative therapy and spironolactone therapy and reported that there was no significant difference between the two therapies. PA is commonly complicated by cardiac dysfunction and metabolic abnormality (cardiometabolic syndrome). Giacchetti et $a .^{17}$ examined the influence of operative therapy and drug therapy on these complications. A comparison was performed between a group of aldosterone-producing adenoma patients who received an adrenalectomy during a mean period of $34 \pm 6$ months and a group of idiopathic hyperaldosteronism patients who received medical therapy during a mean period of $55 \pm 4$ months. In the operative therapy group, the cardiac dysfunction and metabolic abnormality improved (regression), whereas in the medical therapy group, the progression was suppressed (progression avoided). Although both therapies were effective, the operative therapy was more effective than the medical therapy. In most cases, the comparison between operative therapy and medical therapy shows different results that are study dependent because of inconsistent conditions. In addition, a comparison between postoperative aldosterone-producing adenoma and idiopathic hyperaldosteronism after medical therapy is not exactly the same comparison as between operative and medical therapies.

In most cases, spironolactone has been used for drug therapy in PA. According to a limited number of reports on PA, eplerenone administered at doses of $50-400 \mathrm{mg}$ per day reduced blood pressure by 40 to $50 / 20$ to $30 \mathrm{~mm} \mathrm{Hg}$. In PA, the maximum dose of eplerenone is considered to be $400 \mathrm{mg}$ in the United States. When $100 \mathrm{mg}$ per day of eplerenone is administered in a single dose or divided in half $(50 \mathrm{mg} \times 2)$, the divided dose regimen was more effective in decreasing the diastolic blood pressure by $3.6 \mathrm{~mm} \mathrm{Hg}$. Therefore, the method of administration was also evaluated. In addition, there are reports of patients who presented with painful gynecomastia while taking spironolactone whose symptoms completely abated after changing to eplerenone. Eplerenone can be used for patients who have endocrine side effects during treatment with spironolactone.

Karagiannis et al. ${ }^{18}$ compared spironolactone $v s$. eplerenone with regard to blood pressure control in idiopathic hyperaldosteronism patients. ${ }^{18}$ Treatment with spironolactone was started at a dose of $50 \mathrm{mg}$ per day (two divided doses), and treatment with eplerenone was started at a dose of $50 \mathrm{mg}$ per day (two divided doses). The dose was doubled every 4 weeks if the blood pressure was $140 / 90 \mathrm{~mm} \mathrm{Hg}$ or higher. Blood pressure was controlled in $76.5 \%$ of patients in the spironolactone treatment group and $82.4 \%$ of patients in the eplerenone treatment group by week 16. Twenty-four-week treatments with both drugs were almost comparable in regard to hypotensive effects. However, two patients receiving $400 \mathrm{mg}$ per day of spironolactone presented with painful gynecomastia in week 16 of the treatment. Their symptoms were abated by changing their drug to eplerenone $150 \mathrm{mg}$ per day. Two patients receiving $400 \mathrm{mg}$ per day of spironolactone and three patients receiving $150 \mathrm{mg}$ per day of eplerenone presented with hyperkalemia. Although the doses of these drugs used in this study were higher than doses used in Japan, both drugs showed comparable positive blood pressure control. In general, spironolactone may exhibit a stronger hypotensive effect than eplerenone due to their different affinities for MR and the MR antagonist effect of the metabolites when they are administered at the same doses (Table 2). However, contrary to expectations, in his study assessing hypotensive effects in patients with idiopathic hyperaldosteronism, Karaginannis reported that these two agents demonstrated almost equal hypotensive effects.

Parthasarathy et al. ${ }^{19}$ provides information on using spironolactone and eplerenone in PA therapy. The efficacy and safety of spironolactone (75-225 mg once daily) and eplerenone (100-300 mg once daily) were compared in PA patients using the double-blind method. Spironolactone lowered both the systolic and diastolic blood pressure in the seated position beginning at 4 weeks after beginning treatment, with significant differences in the degree of hypotension. The difference increased at 16 weeks after starting the treatment. There was no significant difference in the total adverse drug reactions. More men presented with gynecomastia and more women presented with breast pain in the spironolactone group, with significant differences. Parthasarathy et al. reported the expected result that spironolactone had a stronger hypotensive effect than a higher dose of eplerenone. It is anticipated that the future publication of results from Japanese studies comparing the hypotensive effects of these two agents and the actual results from Japanese clinical practice will be examined.

PA therapy requires blood pressure control and aldosterone inhibition, for which both spironolactone and eplerenone can be used equally. Regarding the hypotensive effect, spironolactone would likely be superior in this regard at an appropriate dose, whereas it is likely that eplerenone may be superior in terms of long-term drug adherence. If a patient experiences no adverse drug reactions to spironolactone and blood pressure is well controlled, then there is no need to change spironolactone to eplerenone or vice versa. If patients 
respond favorably to these therapies, then there is considered to be no clinical difference between the two drugs.

\section{Countermeasures against MR activation during treatment with an ACE inhibitor or ARB: addition of a small amount of MR antagonist}

In this section, we summarize the diseases that require MR activation inhibition during treatment with an ACE inhibitor or ARB. Aldosterone breakthrough is a phenomenon in which plasma aldosterone concentrations increase above pretreatment levels during relatively long-term therapy with an ACE inhibitor or ARB. This phenomenon is noted at a certain frequency regardless of the underlying disease and which renin-angiotensin (RA) inhibitors are used. ${ }^{20-24}$ Aldosterone breakthrough has no influence on the hypotensive effect of RA inhibitors, but it reduces the organ protective effect. Increasing the dose of an ACE inhibitor or an ARB has little benefit as a countermeasure against aldosterone breakthrough, and adding a small amount of an MR antagonist is necessary. In addition, the usefulness of adding an MR antagonist to an ACE inhibitor or ARB in patients without an elevation in the plasma aldosterone concentration has been demonstrated. Some of the research demonstrating this effect include the RALES (Randomized Aldactone Evaluation Study), ${ }^{25}$ EPHESUS (Eplerenone Post-Acute Myocardial Infarction Heart Failure Efficacy and Survival Study) ${ }^{26}$ and EMPHASIS-HF (Eplerenone in Mild Patients Hospitalization and Survival Study in Heart Failure $)^{27}$ studies. Under conditions of heart failure and postmyocardial infarction with left ventricular dysfunction in RALES, EPHESUS and EMPHASIS-HF, it has been reported that MR may be activated by cortisol and aldosterone. Mihailidou and Funder reported that although cortisol is transcriptionally silent to MR under normal conditions, it may become transcriptionally active (MR agonist) under stressed conditions, such as in heart failure. MR antagonists may block these cortisol-MR cascades. ${ }^{28}$

The results of RALES, EPHESUS and EMPHASIS-HF showed an additional effect of spironolactone and eplerenone (all studies were placebo-controlled double-blind studies). Although the standard therapy for heart failure has progressed, the fact that such obvious results have been obtained indicates the importance of the inhibition of MR, even during treatment based on RA inhibitors. In particular, the results of EMPHASIS-HF may strongly influence the future clinical practice for heart failure. In RALES, spironolactone exhibited efficacy at a mean dose of $26 \mathrm{mg}$ per day. In EPHESUS and EMPHASIS-HF, eplerenone exhibited efficacy at doses of 43 and $40 \mathrm{mg}$ per day, respectively. In all of the studies, these drugs were concomitantly used with RA inhibitors, and therefore, the dose of the MR antagonists was reduced or temporarily suspended depending on the serum potassium levels obtained under treatment. In EMPHASISHF, some patients had a low estimated glomerular filtration rate (eGFR). In patients with an eGFR of $30-49 \mathrm{ml}$ per minute per $1.73 \mathrm{~m}^{2}$, treatment with eplerenone was started with an alternate-day administration of $25 \mathrm{mg}$ per day. This measure was taken for the prevention of hyperkalemia. The results showed that a small amount of an MR antagonist, which is needed as a countermeasure against MR activation, has an effect without influencing blood pressure. The required doses of spironolactone (RALES) and eplerenone (EPHESUS and EMPHASIS-HF) are different. Considering the MR antagonistic activity of each drug, these doses are as expected.

We have reported on the additional effects of MR antagonists in patients with diabetic nephropathy (DM nephropathy) and nondiabetic renal disease (non-DM renal disease). Spironolactone of $25 \mathrm{mg}$ per day significantly decreased albuminuria. ${ }^{22,23}$ Thus, when
MR antagonists are used as a countermeasure against MR activation in addition to RA inhibitors, both spironolactone and eplerenone can equally be expected to be effective, even if they are given at a low dose that does not affect blood pressure. It is highly possible that both drugs can be expected to be effective, even with alternate-day administration at a small dose or at reduced doses depending on the potassium levels. In addition, spironolactone rarely causes dosedependent endocrine side effects when administered at a low dose. The results of RALES, however, showed a significantly higher incidence of gynecomastia and breast pain in the spironolactone treatment group (10\%) than in the placebo group (1\%). ${ }^{25}$ When spironolactone is administered, it is important to adjust the dose to prevent it from causing endocrine side effects and hyperkalemia. If endocrine side effects do occur, then eplerenone may be used instead. In actual clinical practice, it is always important to consider that aldosterone or cortisol actions that are beyond the control of RA inhibitors can be suppressed.

\section{Heart failure}

Although this indication overlaps with the countermeasure against MR activation, both drugs are used for the treatment of chronic heart failure in a similar manner. They are considered as an MR antagonist in combination. The Japanese Guidelines for Treatment of Chronic Heart Failure (JCS 2010) encourage the administration of both spironolactone and eplerenone to patients with severe heart failure (New York Heart Association class III or IV) taking loop diuretics and ACE inhibitors (class I, evidence level A). Although RALES and EPHESUS are listed as a basis for this addition, EMPHASIS-HF had not been published at the time the recommendation was made. In actual use, it is preferable to measure serum potassium levels and creatinine levels on day 3 and week 1 of treatment and each month thereafter until month 3 of treatment.

The effects of MR antagonists in heart failure with the primary clinical condition of diastolic dysfunction (heart failure with preserved ejection fraction; HFPEF) are considered to be a future issue. The prognosis for HFPEF has not shown improvement, and there is no proven therapy. JCS 2010 stipulates that MR antagonists are to be used for patients with New York Heart Association classes III and IV (class IIa, evidence level B). Currently, TOPCAT (Treatment of Preserved Cardiac Function Heart Failure with an Aldosterone Antagonist) is being studied, primarily by the NIH (National Institutes of Health) in the United States, to evaluate the efficacy of spironolactone in HFPEF. The results and the results of EMPHASIS-HF will strongly influence future guidelines for the treatment of heart failure.

\section{DIFFERENTIATION OF THE TWO DRUGS}

Next, we summarize the clinical conditions requiring the differentiation of the two drugs. Chronic kidney disease (CKD) is the representative disease. Although both drugs are essentially comparable in efficacy, they require differentiation depending on the differences in the contraindications in Japan. It is also possible that how the drugs are used for hypertensive patients without complications may differ depending on the pharmacological characteristics of each drug.

\section{Chronic kidney disease}

CKD is a common disease that is frequently observed in daily clinical practice. Patients with $\mathrm{CKD}$ are at high risk for cardiovascular diseases, hospitalization and death. CKD must be treated in a comprehensive manner. The management of hypertension is important and requires strict $24 \mathrm{~h}$ blood pressure control, including countermeasures against hypertension during the night and in the 
early morning. The basis of treatment is ACE inhibitors or ARB. Because MR antagonists are administered in addition to ACE inhibitors or $\mathrm{ARB}$, there are accompanying potassium problems. JSH 2009 also suggests that MR antagonists should be used cautiously in hypertensive patients with renal diseases because they are at risk for hyperkalemia. In general, MR antagonists are not recommended for hypertensive patients with renal diseases. Recently, however, it has been shown that MR antagonists are effective for renal protection and exhibit anti-albuminuria as long as they are administered with particular care. ${ }^{22,23,29-34}$ Contraindications for eplerenone in Japan include diabetic patients with microalbuminuria or proteinuria. This contraindication is specific to eplerenone and does not apply to spironolactone in Japan. Therefore, eplerenone cannot be used for patients with DM nephropathy. For this reason, it is necessary to differentiate spironolactone from eplerenone depending on the causative disease in the treatment of CKD in Japan.

For the treatment of diabetic patients with hypertension, it is important to confirm microalbuminuria because eplerenone is contraindicated for patients with this condition. In contrast, eplerenone can be administered to patients without microalbuminuria. Diabetic patients often present with typical salt-sensitive hypertension and rarely respond to RA inhibitors. The hypotensive effect of eplerenone is not reduced in patients with low renin hypertension. ${ }^{2,35,36}$ Therefore, eplerenone can be expected to have a further hypotensive effect when it is added to RA inhibitors. Spironolactone can be used for all stages of hypertension because there is no limitation of DM nephropathy. However, spironolactone is contraindicated for patients with anuria and acute renal failure, so caution is advised. It may be possible to administer spironolactone to dialysis patients, unless they have no anuria. ${ }^{37}$ Serum potassium levels require close monitoring in all patients.

In the treatment of $\mathrm{CKD}$ for which the causative disease is not diabetes mellitus, the use of eplerenone differs. Eplerenone is contraindicated for patients with either moderate or severe renal dysfunction (a creatinine clearance of $<50 \mathrm{ml}$ per minute) because they are at risk for hyperkalemia, although it can be used for patients with mild renal dysfunction (creatinine clearance of not less than $50 \mathrm{ml}$ per minute). For patients with stage 1 (eGFR $\geqslant 90 \mathrm{ml}$ per minute per $1.73 \mathrm{~m}^{2}$ ), stage 2 (eGFR; $60-89 \mathrm{ml}$ per minute per $1.73 \mathrm{~m}^{2}$ ) and some patients with stage 3 (eGFR; $30-59 \mathrm{ml}$ per minute per $1.73 \mathrm{~m}^{2}$ ) CKD, eplerenone administered with attention to the serum potassium levels can be expected to have a further renal protection effect. Currently, EVALUATE (Eplerenone Combination Versus Conventional Agents to Lower Blood Pressure on Urinary Antialbuminuric Treatment Effect Trial) is ongoing as a placebo-controlled, double-blind trial to validate the additional effects of eplerenone on conventional therapies, primarily with RA inhibitors, in Japanese essentially hypertensive patients with albuminuria. ${ }^{38} \mathrm{DM}$ nephropathy patients and patients with an eGFR of $<50 \mathrm{ml}$ per minute per $1.73 \mathrm{~m}^{2}$ for whom eplerenone is contraindicated were excluded from this trial. The result of this trial is expected to have a significant influence on the future treatment of CKD in Japan. Finally, we are not implying that spironolactone is inferior to eplerenone in the treatment of CKD; a small amount of spironolactone is effective in CKD treatment.

\section{Essential hypertension}

Finally, we discuss the use of each drug in patients with essential hypertension who have no cardiovascular complications. Both spironolactone and eplerenone are indicated for hypertension and can be used for the treatment of hypertension. The use of these drugs differs depending on whether they cause concentration-dependent side effects. Eplerenone can be administered up to the maximum dosage, and spironolactone is primarily given at a low dose that will cause no side effects. Eplerenone can be used as monotherapy as long as it can be used up to the maximum dose. Spironolactone, however, must always be given in combination therapy because it is administered at a low dose.

Studies of hypotensive agents with anti-aldosterone activity were initiated 4-5 years after 1953, when aldosterone was discovered after changing a side chain of a steroid skeleton. Among the identified drugs, SC-9420 became available as spironolactone in 1963 in Japan. ${ }^{7}$ Spironolactone is very effective for the treatment of essential hypertension. Many studies have shown that the optimal dose for blood pressure control is regarded to be $100 \mathrm{mg}$ per day. ${ }^{39-42}$ However, its use is problematic because it causes endocrine side effects in $\sim 15-20 \%$ patients at the optimal dose as a hypotensive agent. ${ }^{43-47}$ Spironolactone causes endocrine side effects in a dosedependent manner, and it is considered to be suitable for combination treatment with other drugs at a low dose that does not cause endocrine side effects (up to $\sim 25 \mathrm{mg}$ per day) rather than for monotherapy at $100 \mathrm{mg}$ per day. Spironolactone currently has the most convincing evidence as a fourth drug for patients with resistant hypertension. ${ }^{48-50}$ The efficacy of spironolactone in patients with resistant hypertension when used as a fourth drug was reported in ASCOT-BPLA (Anglo-Scandinavian Cardiac Outcome Trial-Blood Pressure Lowering Arm). ${ }^{51} \mathrm{JSH} 2009$ provides that an MR antagonist at a low dose is effective in resistant hypertension; however, most of this evidence was found with spironolactone. Spironolactone should be used as a combination drug at a low dose rather than independently.

However, eplerenone causes no dose-dependent side effects up to the maximum usable dose of $100 \mathrm{mg}$ in Japan. Therefore, eplerenone can be used as monotherapy. Saruta et al. ${ }^{2}$ have reported the efficacy and safety of eplerenone in Japanese hypertensive patients. The differences in hypotension in response to eplerenone at the maximum usable dose in Japan of $100 \mathrm{mg}$ are $-9.7 /-6.7 \mathrm{~mm} \mathrm{Hg}$ for outpatient blood pressure and $-5.7 / 3.6 \mathrm{~mm} \mathrm{Hg}$ for $24 \mathrm{~h}$ blood pressure. There were no clinically significant serious adverse events. Notably, hyperkalemia and sex hormone-related side effects were not observed in any patient. Most of the patients included in this study had low renin hypertension, and the once-daily administration of eplerenone significantly lowered their casual blood pressure and $24 \mathrm{~h}$ blood pressure. Levy and Funder ${ }^{52}$ titrated a dose of eplerenone from 50 to $100 \mathrm{mg}$ and then to $200 \mathrm{mg}$ in essential hypertension patients until the level of hypotension reached the target level. No doses of eplerenone had a significant effect on the serum potassium levels between the responder group (diastolic blood pressures $<90 \mathrm{~mm} \mathrm{Hg}$ ) and the non-responder group (diastolic blood pressures $\geqslant 90 \mathrm{~mm} \mathrm{Hg}$ ). The authors considered that it is highly possible that the hypotensive mechanism of eplerenone primarily consists of a non-diuretic action (an action via a non-epithelial MR). Our clinical results showed that there was no correlation between the hypotensive responsiveness of eplerenone and the serum potassium levels. ${ }^{3}$ Because the hypertensive mechanism of aldosterone is complicated, it is highly likely that the hypotensive mechanism of eplerenone is also complicated. Particularly for the clarification of clinical conditions in which eplerenone is expected to be effective, it is necessary to accumulate further evidence.

\section{CONCLUSION}

Based on the recently published basic and clinical data on MR antagonists, the target diseases and clinical conditions for this drug appear likely to increase in the future. Spironolactone and eplerenone should primarily be used in the same manner; however, in clinical 
practice, it is considered necessary to use them based on the various perspectives shown in Tables 1 and 2 so they will be effective with minimal adverse reactions.

\section{CONFLICT OF INTEREST}

The author declares no conflict of interest.

1 Ogihara T, Kikuchi K, Matsuoka H, Fujita T, Higaki J, Horiuchi M, Imai Y, Imaizumi T, Ito S, Iwao H, Kario K, Kawano Y, Kim-Mitsuyama S, Kimura G, Matsubara H, Matsuur H, Naruse M, Saito I, Shimada K, Shimamoto K, Suzuki H, Takishita S, Tanahashi N, Tsuchihashi T, Uchiyama M, Ueda S, Ueshima H, Umemura S, Ishimitsu T, Rakugi H, on behalf of The Japanese Society of Hypertension Committee. The Japanese Society of Hypertension Committee for Guidelines for the management of hypertension (JSH 2009). Hypertens Res 2009; 32: 1-107.

2 Saruta T, Kageyama S, Ogihara T, Hiwada K, Ogawa M, Tawara K, Gatlin M, Garthwaite $\mathrm{S}$, Bittman R, Patrick J. Efficacy and safety of the selective aldosterone blocker eplerenone in Japanese patients with hypertension: a randomized, double-blind, placebo-controlled, dose-ranging study. J Clin Hypertens 2004; 6: 175-185.

3 Sato A, Fukuda S. Clinical effects of eplerenone, a selective aldosterone blocker, in Japanese patients with essential hypertension. J Hum Hypertens 2010; 24: 387-394.

4 Jansen PM, Jan Danser AH, Imholz BP, van den Meiracker AH. Aldosterone-receptor antagonism in hypertension. J Hypertens 2009; 27: 680-691.

5 Krozowski ZS, Funder JW. Renal mineralocorticoid receptors and hippocampal corticosterone binding species have identical intrinsic steroid specificity. Proc Nat Acad Sci USA 1983; 80: 6056-6060.

6 Funder JW, Krozowski Z, Myles K, Sato A, Sheppard KE, Young M. Mineralocorticoid receptors, salt, and hypertension. Recent Prog Hormone Res 1997; 52: 247-262.

7 Garthwaite SM, McMahon EG. The evolution of aldosterone antagonists. Mol Cell Endocrinol 2004; 217: 27-31.

8 Greenblatt DJ, Koch-Weser J. Adverse reactions to spironolactone. A report from the Boston Collaborative Drug Surveillance Program. JAMA 1973; 225: 40-43.

$9 \mathrm{Hu}$ X, Li S, McMahon EG, Lala DS, Rudolph AE. Molecular mechanism of mineralocorticoid receptor antagonism by eplerenone. Mini-Rev Med Chem 2005; 5: 709-718.

10 Funder JW. The role of mineralocorticoid receptor antagonists in the treatment of cardiac failure. Expert Opin Investig Drugs 2003; 12: 1963-1969.

11 Overdiek HWPM, Hermens WAJJ, Merkus FWHM. New insights into the pharmacokinetics of spironolactone. Clin Pharmacol Ther 1985; 38: 469-474.

12 McInnes GT, Asbury MJ, Shelton JR, Harrison IR, Ramsay LE, Venning GR, Clarke JM. Activity of sulfur-containing intermediate metabolites of spironolactone. Clin Pharmacol Ther 1980; 27: 363-369.

13 Sica DA. Pharmacokinetics and pharmacodynamics of mineralocorticoid blocking agents and their effects on potassium homeostasis. Heart Fail Rev 2005; 10: 23-29.

14 Struthers A, Krum H, Williams GH. A comparison of the aldosterone-blocking agents eplerenone and spironolactone. Clin Cardiol 2008; 31: 153-158.

15 Catena C, Colussi G, Lapenna R, Nadalini E, Chiuch A, Gianfagna P, Sechi LA. Long term cardiac effects of adrenalectomy or mineralocorticoid antagonists in patients with primary aldosteronism. Hypertension 2007; 50: 911-918.

16 Sechi LA, Novello M, Lapenna R, Baroselli S, Nadalini E, Colussi GL, Catena C. Long-term renal outcomes in patients with primary aldosteronism. JAMA 2006; 295 : 2638-2645.

17 Giacchetti G, Ronconi V, Turchi F, Agostinelli L, Mantero F, Rilli S, Boscaro M. Aldosterone as a key mediator of the cardiometabolic syndrome in primary aldosteronism: an observational study. J Hypertens 2007; 25: 177-186.

18 Karagiannis A, Tziomalos K, Papageorgiou A, Kakafika AI, Pagourelias ED, Anagnostis P, Arthyros V, Mikhailidis DP. Spironolactone versus eplerenone for the treatment of idiopathic hyperaldosteronism. Expert Opin Pharmacother 2008; 9: 509-515.

19 Parthasarathy HK, Menard J, White WB, Young Jr WF, Williams GH, Williams B, Ruilope LM, McInnes GT, Connell JM, MacDonald TM. A double-blind, randomized study comparing the antihypertensive effects of eplerenone and spironolactone in patients with hypertension and evidence of primary aldosteronism. J Hypertens 2011 29: 980-990

20 Sato A, Saruta T. Aldosterone escape during angiotensin-converting enzyme inhibitor therapy in essential hypertensive patients with left ventricular hypertrophy. J Int Med Res 2001; 29: 13-21.

21 Sato A, Saruta T. Aldosterone breakthrough during angiotensin-converting enzyme inhibitor therapy. Am J Hypertens 2003; 16: 781-788.

22 Sato A, Hayashi K, Naruse M, Saruta T. Effectiveness of aldosterone blockade in patients with diabetic nephropathy. Hypertension 2003; 41: 64-68.

23 Sato A, Hayashi K, Saruta T. Antiproteinuric effects of mineralocorticoid receptor blockade in patients with chronic renal disease. Am J Hypertens 2005; 18: 44-49.

24 Sato A, Saruta T, Funder JW. Combination therapy with aldosterone blockade and renin-angiotensin inhibitors confers organ protection. Hypertens Res 2006; 29 211-216.

25 Pitt B, Zannad F, Remme W, Cody R, Castaigne A, Perez A, Palensky J, Wittes J. The effect of spironolactone on morbidity and mortality in patients with severe heart failure. Randomized Aldactone Evaluation Study Investigators. N Engl J Med 1999, 341: 709-717.
26 Pitt B, Remme W, Zannad F, Neaton J, Martinez F, Roniker B, Bittman R, Hurley S, Kleiman J, Gatlin M, Eplerenone Post-Acute Myocardial Infarction Heart Failure Efficacy and Survival Study Investigators. Eplerenone, a selective aldosterone blocker, in patients with left ventricular dysfunction after myocardial infarction. $N$ Engl J Med 2003; 348: 1309-1321.

27 Zannad F, McMurray JJV, Krum H, van Veldhuisen DJ, Swedberg K, Shi H, Vincent J, Pocock SJ, Pitt B, EMPHASIS-HF Study Group. Eplerenone in patients with systolic heart failure and mild symptoms. N Engl J Med 2011; 364: 11-21.

28 Mihailidou AS, Le TYL, Mardini M, Funder JW. Glucocorticoids activate cardiac mineralocorticoid receptors during experimental myocardial infarction. Hypertension 2009; 54: 1306-1312.

29 Pitt B, Reichek N, Willenbrock R, Zannad F, Phillips RA, Roniker B, Kleiman J, Krause $\mathrm{S}$, Burns D, Williams GH. Effects of eplerenone, enalapril, and eplerenone/enalapril in patients with essential hypertension and left ventricular hypertrophy. The 4E-Left Ventricular Hypertrophy Study. Circulation 2003; 108: 1831-1838.

30 Rossing K, Schjoedt KJ, Smidt UM, Boomsma F, Parving HH. Beneficial effects of adding spironolactone to recommended antihypertensive treatment in diabetic nephropathy. Diabetes Care 2005; 28: 2106-2112.

31 Schjoedt KJ, Rossing K, Juhl TR, Boomsma F, Tarnow L, Rossing P, Parving HH. Beneficial impact of spironolactone on nephritic range albuminuria in diabetic nephropathy. Kidney Int 2006; 70: 536-542.

32 Bianchi S, Bigazzi R, Campese VM. Antagonists of aldosterone and proteinuria in patients with CKD: an uncontrolled pilot study. Am J Kidney Dis 2005; 46: 45-51.

33 Chrysostomou A, Pedagogos E, MacGregor L, Becker GJ. Double-blind placebocontrolled study on the effect of the aldosterone receptor antagonist spironolactone in patients who have persistent proteinuria and are on long-term angiotensin-converting enzyme inhibitor therapy, with or without an angiotensin II receptor blocker. Clin J Am Soc Nephrol 2006; 1: 256-262.

34 Epstein M, Williams GH, Weinberger M, Lewin A, Krause S, Mukherjee R, Patni R, Beckerman B. Selective aldosterone blockade with eplerenone reduces albuminuria in patients with type 2 diabetes. Clin J Am Soc Nephrol 2006; 1: 940-951.

35 Flack JM, Oparil S, Pratt JH, Roniker B, Garthwaite S, Kleiman JH, Yang Y, Krause SL, Workman D, Saunders E. Efficacy and tolerability of eplerenone and losartan in hypertensive black and white patients. J Am Coll Cardiol 2003; 41: 1148-1155.

36 Weinberger M, White WB, Ruilope LM, MacDonald TM, Davidson RC, Roniker B, Patrick JL, Krause SL. Effects of eplerenone versus losartan in patients with low-renin hypertension. Am Heart J 2005; 150: 426-433.

37 Gross E, Rothstein M, Dombek S, Juknis HI. Effect of spironolactone on blood pressure and renin-angiotensin-aldosterone system in oligo-anuric hemodialysis patients. $A m$ Kidney Dis 2005; 46: 94-101.

38 Ando K, Ohtsu H, Arakawa Y, Kubota K, Yamaguchi T, Nagase M, Yamada A, Fujita T, on behalf of the EVALUATE Study Investigators. Rational and design of the Eplerenon combination versus conventional agents to lower blood pressure on urinary antialbuminuric treatment effect (EVALUATE) trial: a double-blinded randomized placebocontrolled trial to evaluate the antialbuminuric effects of an aldosterone blocker in hypertensive patients with albuminuria. Hypertens Res 2010; 33: 616-621.

39 Sundsfjord JA, Odegaard AE. Renin levels and spironolactone treatment in general practices: similar blood pressure lowering effect of spironolactone in low and normal renin patients. Eur J Clin Invest 1977; 7: 389-392.

40 Ogilvie RI, Piafsky KM, Ruedy J. Antihypertensive responses to spironolactone in normal renin hypertension. Clin Pharmacol Ther 1978; 24: 525-530.

41 Skluth HA, Gums JG. Spironolactone: a re-examination. Ann Pharmacol 1990; 24 $52-59$.

42 Wolf RI, Mendlowitz M, Roboz J, Styan GPH, Kornfeld P, Weigl A. Treatment of hypertension with spironolactone. Double-blind study. JAMA 1966; 198: 121-127.

43 Jeunemaitre X, Chatellier G, Kraft-Jais C, Charru A, Devries C, Plouin PF, Corvol P, Menard J. Efficacy and tolerance of spironolactone in essential hypertension. $\mathrm{Am} \mathrm{J}$ Cardiol 1987; 60: 820-825.

44 Jeunemaitre X, Kreft-Jais C, Chatellier G, Julien J, Degoulet P, Plouin PF, Menard J, Corvol P. Long-term experience of spironolactone in essential hypertension. Kidney Int 1988; 34: S14-S17.

45 Huffman DH, Kampmann JP, Hignite CE, Azarnoff DL. Gynecomastia induced in normal males by spironolactone. Clin Pharmacol Ther 1978; 24: 465-473.

46 Schersten B, Thulin T, Kuylenstierna J, Engstrom M, Karlberg BE, Tolagen K, Nordlander S, Nilsson G. Clinical and biochemical effects of spironolactone administered once daily in primary hypertension. Multicenter Sweden Study. Hypertension 1980; 2: 672-679.

47 Spark RF, Melby JC. Aldosteronism in hypertension: the spironolactone response test. Ann Intern Med 1968; 69: 685-691.

48 Nishizaka MK, Zaman MA, Calhoun DA. Efficacy of low-dose spironolactone in subjects with resistant hypertension. Am J Hypertens 2003; 16: 925-930.

49 Ouzan J, Perault C, Lincoff AM, Carre E, Mertes M. The role of spironolactone in the treatment of patients with refractory hypertension. Am J Hypertens 2002; 15 333-339.

50 Lane DA, Shah S, Beevers G. Low-dose spironolactone in the management of resistant hypertension: a surveillance study. J Hypertens 2007; 25: 891-894.

51 Chapman N, Dobson J, Wilson S, Dahlof B, Sever PS, Wedel H, Poulter NR. on behalf of the Anglo-Scandinavian Cardiac Outcome Trial Investigation. Effect of spironolactone on blood pressure in subjects with resistant hypertension. Hypertension 2007, 49: 839-845.

52 Levy DG, Funder JW. Distinguishing the antihypertensive and electrolyte effects of eplerenone. J Clin Endocrinol Metab 2004; 89: 2736-2740. 